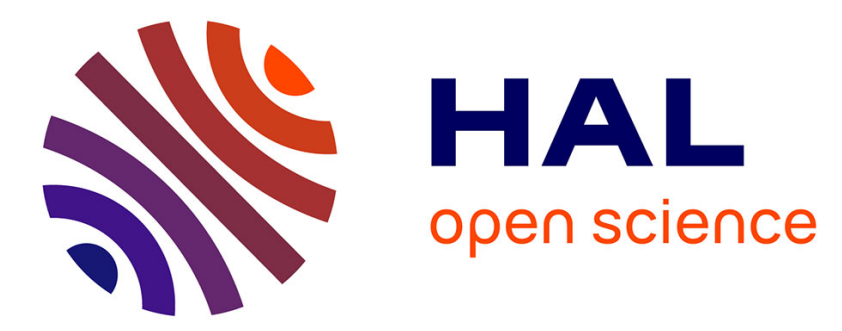

\title{
Distance-dependent plasma composition and ion energy in high power impulse magnetron sputtering
}

\author{
Arutiun P Ehiasarian, Joakim Andersson, André Anders
}

\section{To cite this version:}

Arutiun P Ehiasarian, Joakim Andersson, André Anders. Distance-dependent plasma composition and ion energy in high power impulse magnetron sputtering. Journal of Physics D: Applied Physics, 2010, 43 (27), pp.275204. 10.1088/0022-3727/43/27/275204 . hal-00597824

\section{HAL Id: hal-00597824 \\ https://hal.science/hal-00597824}

Submitted on 2 Jun 2011

HAL is a multi-disciplinary open access archive for the deposit and dissemination of scientific research documents, whether they are published or not. The documents may come from teaching and research institutions in France or abroad, or from public or private research centers.
L'archive ouverte pluridisciplinaire HAL, est destinée au dépôt et à la diffusion de documents scientifiques de niveau recherche, publiés ou non, émanant des établissements d'enseignement et de recherche français ou étrangers, des laboratoires publics ou privés. 


\title{
Distance-dependent plasma composition and ion energy in
}

\section{high power impulse magnetron sputtering}

\author{
Arutiun P Ehiasarian', Joakim Andersson ${ }^{2,3}$ and André Anders ${ }^{2}$ \\ 1) Materials and Engineering Research Institute, Sheffield Hallam University, Howard \\ St., Sheffield S1 1WB, United Kingdom, a.ehiasarian@shu.ac.uk \\ 2) Lawrence Berkeley National Laboratory, University of California, 1 Cyclotron Road, \\ Berkeley, California 94720, USA \\ 3) now at Ångström Laboratory, Uppsala University, Uppsala, Sweden \\ Short title: Distance-dependent ion flux in HIPIMS
}

\begin{abstract}
The plasma composition of high power impulse magnetron sputtering (HIPIMS) has been studied for titanium and chromium targets using a combined energy analyzer and quadrupole mass spectrometer. Measurements were done at distances from 50 to $300 \mathrm{~mm}$ from the sputtering target. $\mathrm{Ti}$ and $\mathrm{Cr}$ are similar in atomic mass but have significantly different sputter yields, which gives interesting clues on the effect of the target on plasma generation and transport of atoms. The Ti and Cr HIPIMS plasmas operated at a peak target current density of $\sim 0.5 \mathrm{~A} \mathrm{~cm}$ 2. The measurements of the argon and metal ion content as well as the ion energy distribution functions showed that: (1) singly and doubly charged ions were found for argon as well as for the target metal, (2) the majority of ions were singly charged argon for both metals at all distances investigated, (3) the Cr ion density was maintained to further distances from the target than Ti. Gas rarefaction was identified as a main factor promoting transport of metal ions, with the
\end{abstract}


stronger effect observed for $\mathrm{Cr}$, the material with higher sputter yield. $\mathrm{Cr}$ ions were found to displace a significant portion of the gas ions, whereas this was less evident in the Ti case. The observations indicate that the presence of metal vapour promotes charge exchange and reduces the electron temperature and thereby practically prevents the production of $\mathrm{Ar}^{2+}$ ions near the target. The content of higher charge states of metal ions depends on the probability of charge exchange with Argon.

52.25.Fi Transport properties

52.77.Dq Plasma-based ion implantation and deposition

52.80.Hc Glow; corona

52.70.Nc Particle measurements

Submitted to. Journal of Physics D: Applied Physics 


\section{Introduction}

High Power Impulse Magnetron Sputtering (HIPIMS) is increasingly applied in industrial thin film deposition processes, and the range of deposition materials is growing [1-7]. The prime benefit of HIPIMS discharges is the increase in the metal ion current compared to conventional DC sputtering, allowing for improved substrate-film interface tailoring and film texture tuning by controlling the kinetic ion energy in the deposition process, not unlike what has been studied and used in cathodic arcs $[8,9]$.

The target material in HIPIMS operation strongly influences the total plasma density at the substrate, the metal ion to gas ion ratio, the speed of evolution of the discharge current, and the establishment of steady state $[10,11]$. The transport of particles from the target to the substrate is consistent with ambipolar diffusion for metal ions and classical diffusion for metal neutrals [12]. However the interaction of particles with the gas phase and dependence of transport on the target material are still not well understood. Additional measurements like in the present contribution aim to provide more details about the underlying physical mechanisms.

As shown by Hecimovic et al. [13], the metal and gas ion energy distribution functions are significantly affected by the background pressure of the process gas. This was related to the number of collisions of ions during their flight to the spectrometer. A similar effect on the number of collisions of target atoms and ions when travelling from the target to a substrate or collector can be observed by measuring species and distribution functions at different distances from the target. Recent developments in the tuneable-diode laser induced fluorescence (TD-LIF) technique have obtained in-situ measurements of spatially resolved velocity, energy and flux distributions of sputtered particles in conventional magnetron sputtering discharges [14]. At the same time, the phenomenon of gas rarefaction in magnetrons is strongly present in HIPIMS plasma discharges [15]. This leads to local reduction of pressure and associated increase in collision mean free path. 
These experiments can also provide clues on how to best utilize the flux of different species - gas ions, metal ions and metal neutrals - during deposition of thin films. Chromium and titanium targets were selected for this study because those materials have similar mass, different sputter yields and are both important for hard coatings applications.

\section{Experimental Details}

The experiments were carried out at Berkeley Lab in a stainless steel vacuum chamber cryogenically pumped to a base pressure of $<10^{-4} \mathrm{~Pa}$ and backfilled with $4 \mathrm{~N}$ purity argon with a flow rate of $20 \mathrm{sccm}$. The chamber had an adjustable gate valve setting the pumping speed for an operational pressure of $0.64 \mathrm{~Pa}$ as measured with a Baratron ${ }^{\circledR}$ gauge. Figure 1 shows a simplified schematic of the experimental arrangement.

The magnetron was a nominally magnetically balanced gun (US Inc.) with a planar 50 $\mathrm{mm}$ ( 2 inch) diameter target having a maximum magnetic field strength of $47 \mathrm{mT}$ parallel to the target surface in the "racetrack" region of the $6.35 \mathrm{~mm}(1 / 4$ inch) thick target. The sputter target (Cr or $\mathrm{Ti}$ ) was directly facing the sampling orifice of the energy-resolving mass spectrometer (described later). The magnetron gun was mounted on a long shaft that allowed the distance, $d$, between the target surface and the sampling orifice to be changed from $d=50 \mathrm{~mm}$ to $300 \mathrm{~mm}$.

High power pulses were provided to the target by a SPIK2000A pulser (Melec GmbH) charged by a Pinnacle DC power supply (Advanced Energy). The pulse voltage was maintained constant throughout the pulse as monitored by a 100:1 voltage probe (Tektronix) connected to the target feedthrough. The pulse voltage was set by the DC charging unit, while the pulse duration, repetition rate, and arc suppression were handled by the pulser unit. The current was measured using a broadband inductive current monitor (Pearson, $0.01 \mathrm{~V} / \mathrm{A}$ ). All electrical signals were recorded and stored on a digital oscilloscope (Tektronix TDS5104B). Figures 2 (a) and (b) show examples of the voltage and current pulses. Constant pulse length of $150 \mu$ s and duty cycle of $1 \%$ were used for all measurements. 


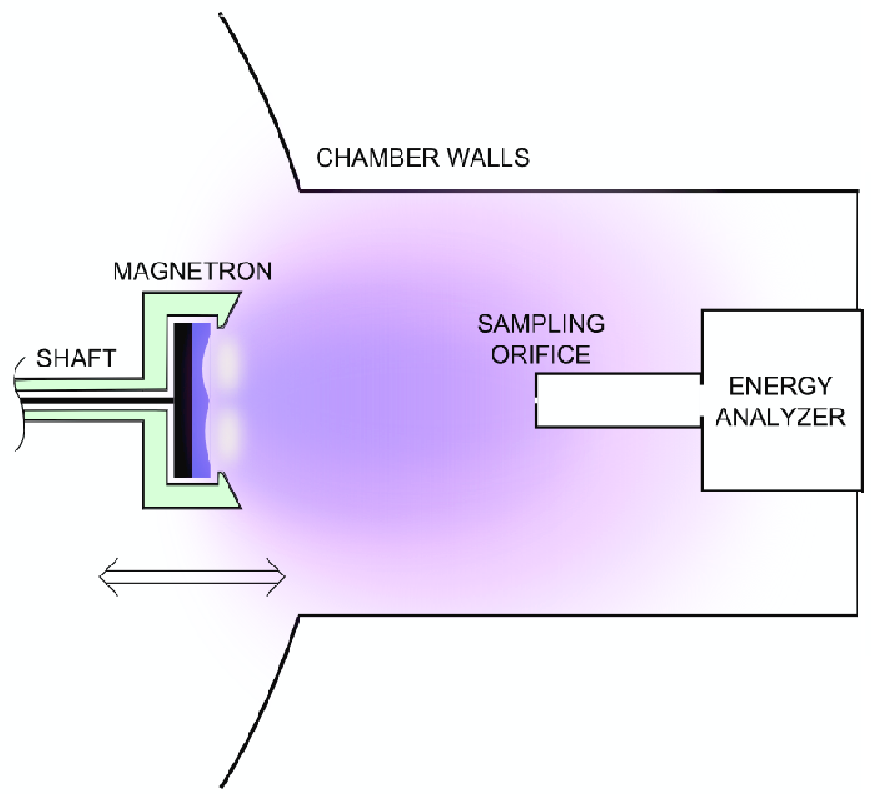

Figure 1. Schematic presentation of the experimental apparatus showing the magnetron gun mounted on a moveable shaft and the fixed energy-resolving mass spectrometer.

For chromium, the maximum available voltage of $-1000 \mathrm{~V}$ was used resulting in a peak current of $7.5 \mathrm{~A}$ (current density $0.38 \mathrm{~A} \mathrm{~cm}^{-2}$ when averaged over the target area). For titanium, a lower voltage of $-870 \mathrm{~V}$ was used to obtain a comparable peak current. However, with $9.5 \mathrm{~A}$ $\left(0.48 \mathrm{~A} \mathrm{~cm}^{-2}\right)$ it was still higher than that for chromium. Although the voltage was constant throughout the pulse, the current increased sharply in the beginning of each pulse and then decreased to a level of 4.5 $\mathrm{A}$ and 3.5 $\mathrm{A}$ for $\mathrm{Cr}$ and $\mathrm{Ti}$, respectively. The pulse shapes were not exactly the same for both materials: higher currents were not attainable for $\mathrm{Cr}$ whereas the $\mathrm{Ti}$ discharge could not be maintained at lower currents. However, the difference in peak current is regarded small for the purposes of further discussions. The current and voltage levels and shapes 
indicate that the magnetron was operated in HIPIMS mode but not in the sustained self-sputtering mode, as discussed in section 4. The shape of the current is also different. As discussed previously $[10,11]$, the current of the discharge falls even at constant voltage due to gas rarefaction and decreasing gas plasma density. That is, unless one considers high powers or a very high yield material where sustained self-sputtering is supported and metal plasma replenishes gas plasma losses. In the $\mathrm{Cr}$ case, the sputter yield by $\mathrm{Ar}$ and $\mathrm{Cr}$ ions is high and a significant number of metal ions are produced adding a component of $\mathrm{Cr}$ ion self-sputtering current to the discharge current. In addition, the production of $\mathrm{Cr}^{2+}$ ions is intensified, which promote a higher secondary electron emission coefficient. This allows the maintaining of a relatively high current over a longer time within the pulse. In the case of $\mathrm{Ti}$, in contrast, the sputter yield is significantly lower and the transient phase of high current gas discharge quickly decays by rarefaction and the post-peak level is not much enhanced by the current of metal ions which cause self-sputtering.

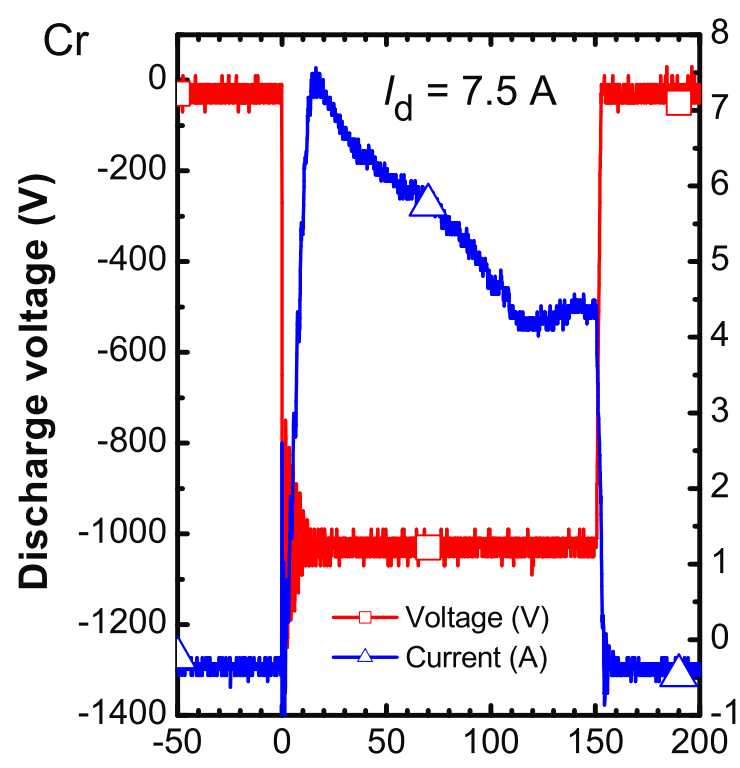

a) Time ( $\mu s)$

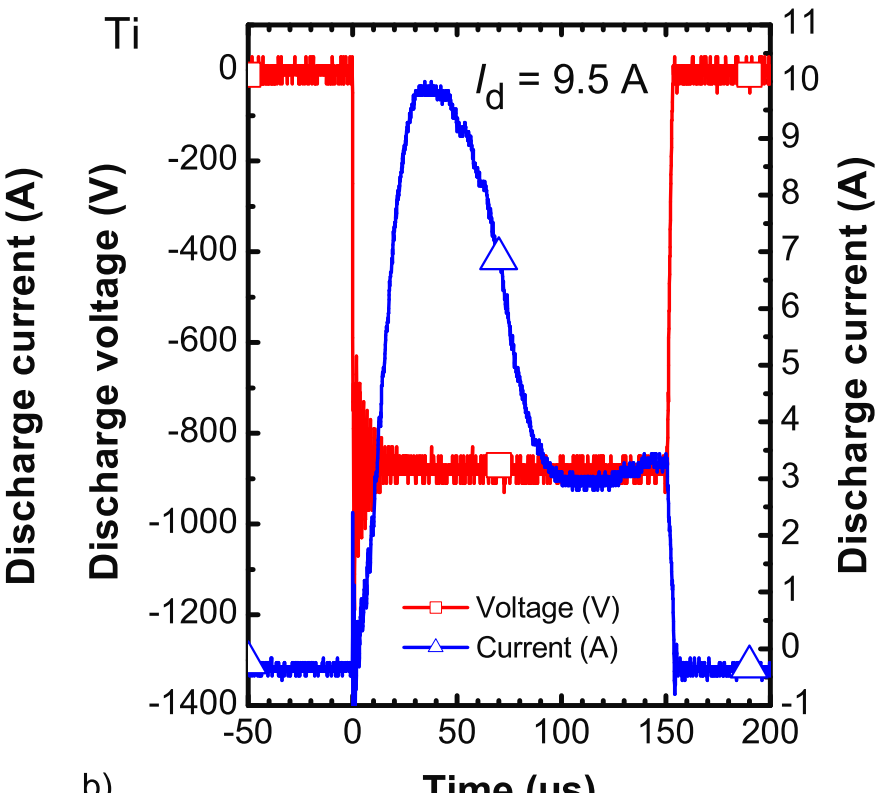

b)

Time $(\mu s)$

Figure 2. Voltage and current of HIPIMS discharges of (a) Cr and (b) Ti at $4.8 \mathrm{mTorr}(0.64 \mathrm{~Pa})$. 
As indicated in Figure 1, the magnetron centre directly faced the orifice of the energyresolving mass spectrometer (EQP by HIDEN Ltd.). A small deviation from the perfectly axially symmetric position cannot be excluded because the gun was mounted on a long shaft. As was shown by Horwat et al. [16], even as there is an angular dependence in the average charge state and deposition rate for HIPIMS, the variation is small for angles close to the target normal. The sampling orifice of the analyser was grounded and had a diameter of $100 \mu \mathrm{m}$. The acceptance angle of the instrument is less than $2^{\circ}$ and as such the particles collected represent a relatively small fraction of all ions. However, it is expected that ions have a relatively random velocity vector and ion energy distribution function (IEDF) measurements in facing and $58^{\circ}$ orientation of the spectrometer have shown negligible differences in IEDFs (compare [17] and [13]).

The spectrometer was differentially pumped using a 70 1/s turbo pump to ensure that the trajectories of sampled particles inside the instrument were collisionless. The IEDF of the ion species in the HIPIMS plasma were determined in time-averaged mode. The relative error (in \%) in mass spectroscopy measurements was determined from the count rate according to the formula $100 /$ sqrt(count rate) as recommended by the manufacturer.

\section{Results}

\subsection{Plasma composition in HIPIMS of $\mathrm{Cr}$ and $\mathrm{Ti}$}

The variation of the $\mathrm{Ar}^{1+}$ ion count rate with distance from the target reveals strong differences between HIPIMS of Cr, shown in Figure 3(a), and HIPIMS of Ti, shown in Figure 3(b). In the case of HIPIMS of $\mathrm{Cr}$, the $\mathrm{Ar}^{1+}$ count rate is very low near the target and increases appreciably with distance, whereas it steadily decreases for HIPIMS of Ti. Furthermore, the flux of $\mathrm{Cr}^{1+}$ to the orifice is maintained until longer distances of $d=200 \mathrm{~mm}$ before it starts to diminish, while the flux of $\mathrm{Ti}^{1+}$ starts to drop as early as $d=100 \mathrm{~mm}$. 
A slightly higher content of $\mathrm{Ti}^{2+}$ than $\mathrm{Cr}^{2+}$ is observed and a discussion on mechanisms of creation is given in Section 4.2.

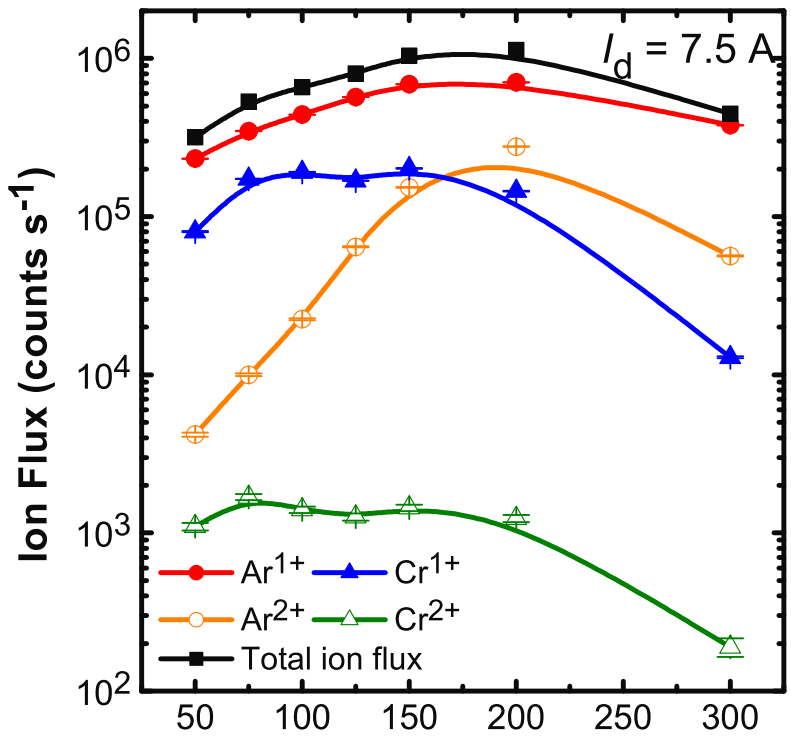

a)

Distance from Target $(\mathrm{mm})$

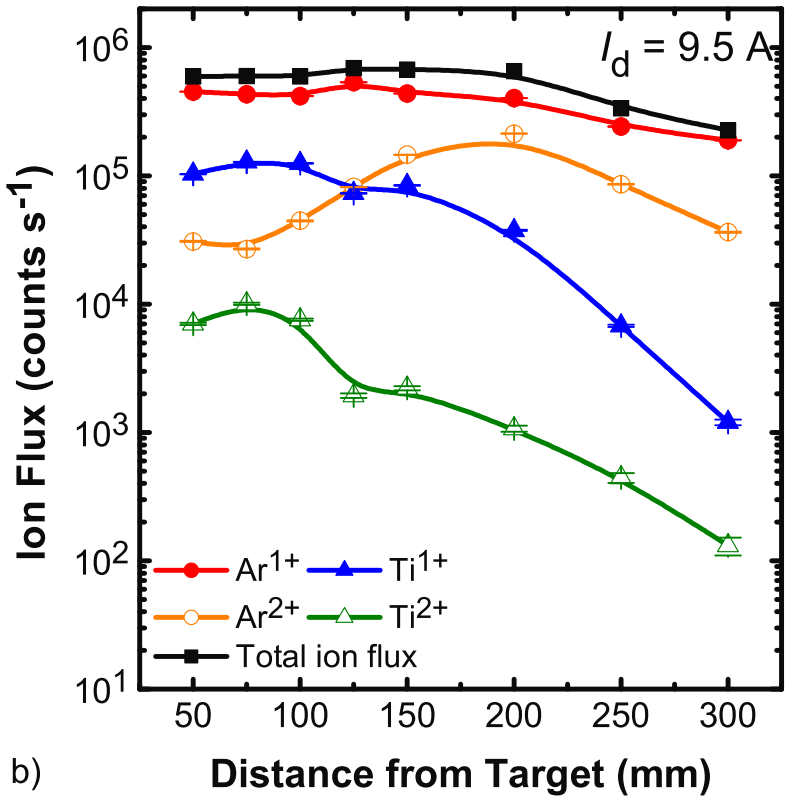

b)

\section{Distance from Target $(\mathrm{mm})$}

Figure 3. Ion count rate (integrated over the energy distribution function) as a function of distance for HIPIMS of (a) $\mathrm{Cr}$ and (b) Ti.

Figure 4(a) shows the normalized ion content of HIPIMS Cr plasma measured with increasing distance $d$. The dominating ions are $\mathrm{Ar}^{1+}$ at all distances. Their fraction remains constant in the range $62-72 \%$ up to $d=300 \mathrm{~mm}$ when it rises to $85 \%$. $\mathrm{The}^{\mathrm{Cr}^{1+}}$ ion content exhibits strong variations reaching a maximum of $30 \%$ at $75 \mathrm{~mm}$. The figure shows that the plasma is rich in metal ions at distances less than $150 \mathrm{~mm}$, whereas the plasma consists of ionized gas at greater distances. It is interesting to note that concurrently with the drop in metal ion content, the content of $\mathrm{Ar}^{2+}$ ions increases sharply and at a distance of $170 \mathrm{~mm}$ overtakes that of $\mathrm{Cr}^{1+}$. 


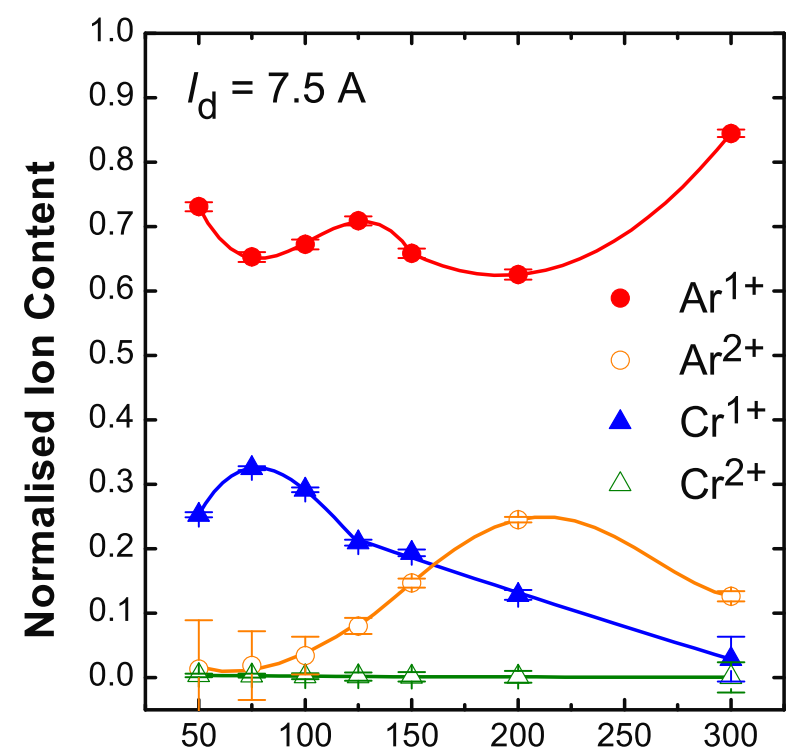

(a) Distance from Target (mm)

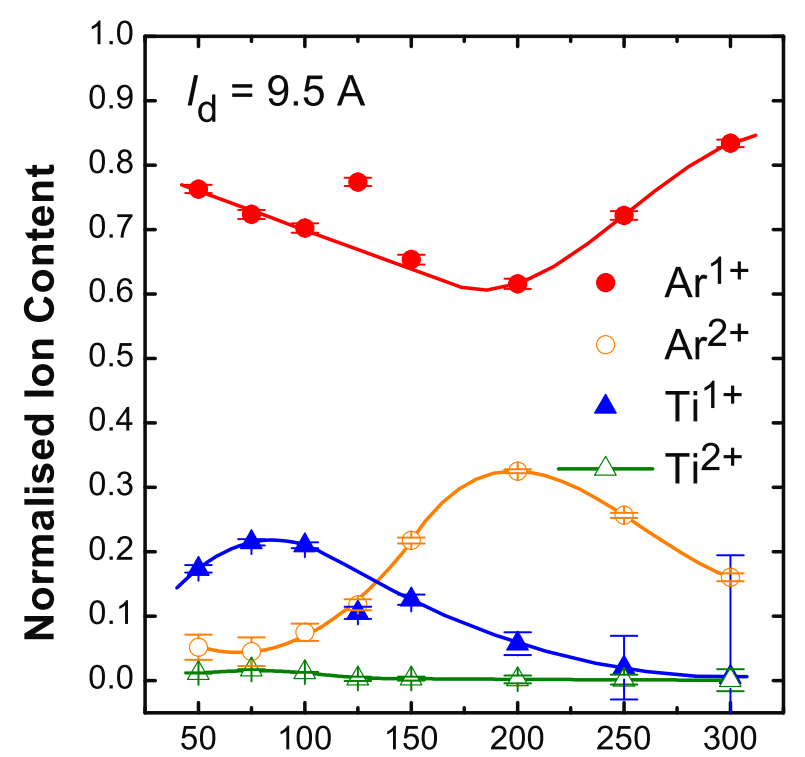

(b)

\section{Distance from Target ( $\mathrm{mm}$ )}

Figure 4. Normalised ion content as a function of distance from the target for HIPIMS of (a) $\mathrm{Cr}$ and (b) Ti. Lines are drawn to guide the eye.

In the case of HIPIMS of Ti, Fig. 4(b), the $\mathrm{Ar}^{2+}$ content is observed to rise even more sharply at long distances compared to the Cr case. Ar ${ }^{2+}$ overtakes the metal at a distance of 125 $\mathrm{mm}$, which is shorter than in the $\mathrm{Cr}$ case. $\mathrm{The}^{\mathrm{Ti}^{1+}}$ metal ion content reaches a lower maximum value of $22 \%$ compared to $\mathrm{Cr}^{1+}$ with $33 \%$.

A local maximum of the $\mathrm{Ar}^{1+}$ signal is observed at $\sim 125 \mathrm{~mm}$ for both HIPIMS of $\mathrm{Cr}$ and HIPIMS of Ti. As indicated by the error bars, these excursions are an existing phenomenon and not a fluctuation in the measurement.

\subsection{Ar gas ion energy}

Figure 5(a) shows the IEDF of $\mathrm{Ar}^{1+}$ ions at different distances from the target for HIPIMS with a chromium target. At a distance $d=50 \mathrm{~mm}$, the IEDF exhibits a main peak at low energy 
and a pronounced high energy tail reaching approximately $8 \mathrm{eV}$. With increasing distance from the target, the tail gradually diminishes and becomes negligible at $d=150 \mathrm{~mm}$. 

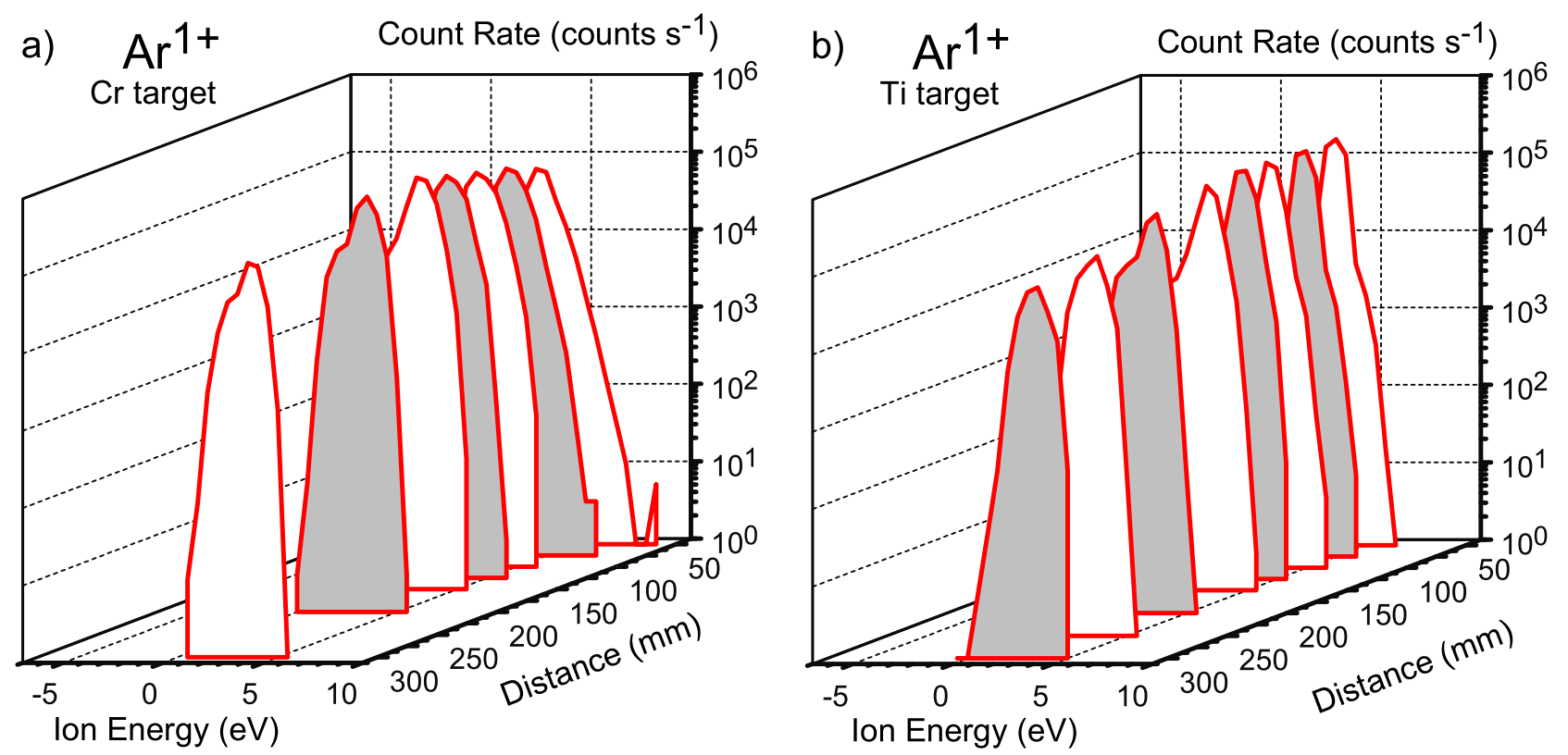

Figure 5. Ion energy distribution functions of $\mathrm{Ar}^{1+}$ ions in HIPIMS discharges utilizing (a) $\mathrm{Cr}$ and

(b) Ti targets. Ion energies are presented in electronvolts corresponding to the potential settings within the mass spectrometer.

In the case of HIPIMS of Ti, Fig. 5(b), the high energy tail of $\mathrm{Ar}^{1+}$ is significantly smaller reaching only up to $6 \mathrm{eV}$ and is maintained to a distance up to $125 \mathrm{~mm}$.

\subsection{Metal ion energy}

The $\mathrm{Cr}^{1+}$ IEDF changes with distance. Figure 6a shows that the main group of ions has a low energy of about $4 \mathrm{eV}$. Near the target, $d=50 \mathrm{~mm}$, the IEDF contains a significant high energy tail. At larger distances, the low energy peak is narrower and of less intensity. Remnants of the high energy tail are still detected at $200 \mathrm{~mm}$. 

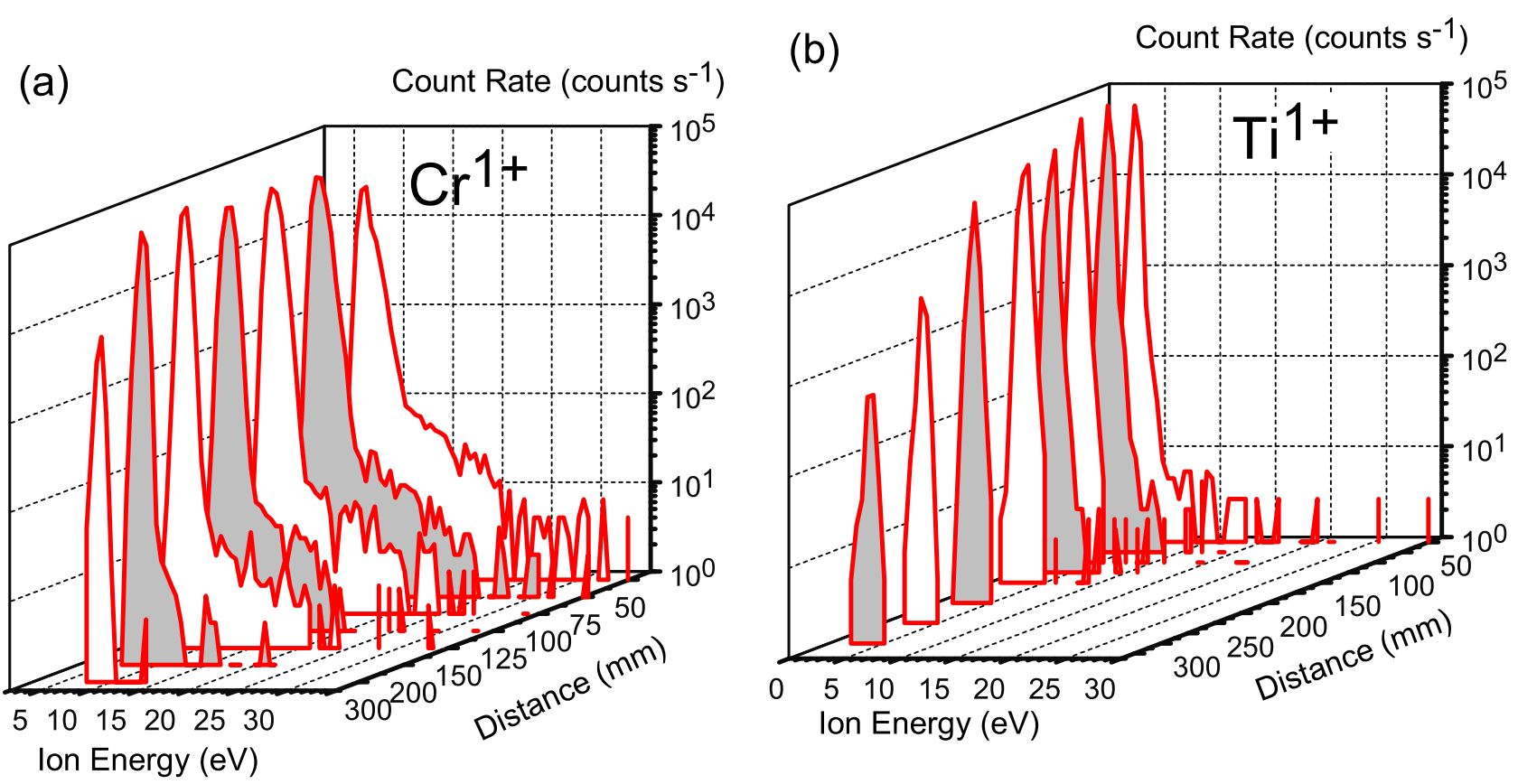

Figure 6. Ion energy distribution function of a) $\mathrm{Cr}^{1+}$ ions in HIPIMS with a chromium target and b) $\mathrm{Ti}^{1+}$ ions in HIPIMS with a titanium target. Ion energies are presented in electronvolts as determined by the potential settings within the mass spectrometer.

For $\mathrm{Ti}^{1+}$ (Figure $6 \mathrm{~b}$ ) the high energy tail component is much smaller than in the $\mathrm{Cr}$ case, both in energy and in relative intensity.

\section{Discussion}

Differences in total plasma density and electron temperature produced in HIPIMS with Ti and $\mathrm{Cr}$ targets have been observed by Vetushka et al. [18]; our measurements provide additional insight into the spatial distribution of metal and gas ions as well as their energies utilising a different magnetron, power supply, process chamber, and measuring configuration.

\subsection{Gas ions}


The differences in the spatial distribution of $\mathrm{Ar}^{1+}$ in HIPIMS of $\mathrm{Ti}$ and $\mathrm{Cr}$ plasmas shown in Figures 3(a) and 3(b) could be attributed to gas rarefaction effects [19]. It may be considered that $\mathrm{Ar}^{1+}$ ions are mainly produced by electron impact ionisation from neutral gas atoms. In this case, the ions and their parent atoms are expected to have a similar kinetic energy distribution function. The density of process gas atoms in the vicinity of the target is known to be affected by the presence of sputtered metal. In the case of $\mathrm{Cr}$, the flux of metal atoms produced at the target is both very high due to (i) the high sputtering yield of the material and (ii) due to the relatively high energy of the sputtered atoms resulting from the collision cascade producing the sputtered atoms [20]. When interacting with the Ar gas, these particles transfer their kinetic energy, mainly via elastic collisions, leading to a net transfer of momentum ("sputter wind"), and heating of the gas via successive, randomizing collisions; both causing a reduced gas density near the target, known as rarefaction [19]. The momentum transfer manifests itself in the observed high energy of Ar ions, Fig. 5(a).

In the case of HIPIMS of chromium, the density of metal vapour is high due to the high sputter yield. This results in high energy input to the background gas through elastic collisions, and can explain its high energy tail. Kadlec [15] has calculated a rarefaction degree of $70 \%$ in HIPIMS in the vicinity of the target due to this process. In the current experiment we observe a high number of $\mathrm{Cr}$ metal ions near the target, Fig. 4(b), which may amplify the strong rarefaction.

In the case of titanium, the sputter yield and, consequently, the flux of metal atoms are lower. Additionally, the instantaneous power is slightly lower thus less energy is put into the system. The combination of these factors leads to a much weaker rarefaction effect. Hence, the high energy tail of Ar ions in the Ti sputter plasmas, Fig. 5(b), is smaller compared to the $\mathrm{Cr}$ sputter plasmas. Since the effect of rarefaction is weaker in the Ti discharge, the count rate of $\mathrm{Ar}^{1+}$ does not increase with distance near the target, as it does in the $\mathrm{Cr}$ discharge, but rather displays a steady decay with distance. 
The normalised content of $\mathrm{Ar}^{1+}$ is slightly augmented at $\sim 125 \mathrm{~mm}$ (Figure 4a and $4 \mathrm{~b}$ ). This may be coupled to non-uniformities in the magnetic field structure that affect local power dissipation and trapping of plasma; subject to further investigations. It is understood that much of the energy dissipation, and ionization, occurs in the magnetized negative glow, rather than in the sheath near the target. Clearly, ionization is originally powered by electrons that gain energy in the sheath but that travel to great lengths before colliding and losing energy. Magnetization and the closed drift of electrons in the magnetron's field structure ensure that ionization and electron thermalization occur within a few centimetres from the target even as the "great lengths" of the electron's mean free path can exceed the size of the discharge zone.

\subsection{Metal ions}

The content of singly charged metal ions was observed to be higher for chromium than for titanium. This could be attributed to the sputter yield of the respective materials, as follows. The metal ions have a significantly lower first ionisation potential $(5.6 \mathrm{eV}$ for $\mathrm{Cr}$ and $6.5 \mathrm{eV}$ for $\mathrm{Ti}$ ) than $\operatorname{Ar}(\underline{15.76 \mathrm{eV}}))_{-}$Metal ions can be created through collisions with those electrons that have energy above their first ionization energy, whereas the formation of Ar gas ions would require electron energies above $15.76 \mathrm{eV}$. Assuming, for the time being, a Maxwellian electron energy distribution function (EEDF) with a temperature of $3 \mathrm{eV}$, we can derive that approximately $30 \%$ of all electrons lie within the range for metal ion creation whereas only $<1 \%$ are able to generate $\mathrm{Ar}^{1+}$ and $\mathrm{Ar}^{2+}$. However, calculations [21] have shown that the EEDF of a magnetron discharge (and in general glow discharge) may significantly deviate from Maxwellian by exhibiting a nonMaxwellian hot electron tail. Instead of the characteristic Maxwellian exponential drop, the tail comprises a rather constant electron density at all energies between $\sim 25 \mathrm{eV}$ and up to the full cathode potential. According to this model, $\mathrm{Ar}^{1+}$ and $\mathrm{Ar}^{2+}$ could be produced by almost $5 \%$ of electrons through direct double ionisation and/or possibly inner-shell ionisation. The effect is weaker in HIPIMS due to its low mean electron energy $\langle\mathrm{E}\rangle$ of $3 \mathrm{eV}$ compared to conventional magnetrons, where $\langle\mathrm{E}\rangle$ can exceed $5 \mathrm{eV}$. The high density in HIPIMS plasma promotes 
electron-electron energy exchange and therefore the EEDF in HIPIMS plasmas should be much closer to the equilibrium Maxwellian than in conventional magnetron discharges.

Additionally, the metal vapour absorbs energy from a large proportion of electrons and its presence cools the overall distribution. Gas ions have a high ionisation threshold whereas metal is more readily ionized. Thus materials with higher sputtering yield produce plasmas with greater proportion of metal ions compared to gas ions [13].

For double charged metal ions, the relation is reversed - the amount of $\mathrm{Cr}^{2+}$ is less than $\mathrm{Ti}^{2+}$. The content of higher ionisation states such as $\mathrm{Cr}^{2+}$ and $\mathrm{Ti}^{2+}$ depends on the balance of production by electron impact ionization and reduction mainly by charge exchange and other processes. Charge exchange could proceed with gas or with neutral atoms of the same metal.

A significant factor is charge exchange with $\mathrm{Ar}$ neutrals, for example: $\mathrm{Cr}^{2+}+\mathrm{Ar} \rightarrow \mathrm{Cr}^{1+}+\mathrm{Ar}^{1+}+\Delta E$, where $\Delta \mathrm{E}$ is an energy defect as defined by the difference in ionisation potentials of $\mathrm{Cr}^{2+}$ of $16.49 \mathrm{eV}$ and $\mathrm{Ar}^{1+}$ of $15.76 \mathrm{eV}$. In the case of $\left(\mathrm{Cr}^{2+}+\mathrm{Ar}^{0}\right)$, charge exchange is highly probable because energy of $0.73 \mathrm{eV}$ is released (positive energy defect). In contrast, $\left(\mathrm{Ti}^{2+}+\mathrm{Ar}^{0}\right)$ charge exchange is unlikely since $\mathrm{Ti}^{2+}$ has a lower ionisation potential of $13.6 \mathrm{eV}$ which gives a negative energy defect of $-2.16 \mathrm{eV}$ and requires an initial kinetic energy of ions of $4.75 \mathrm{eV}$ to proceed. This discussion indicates that $\mathrm{Cr}^{2+}$ would be strongly depleted through charge exchange whereas $\mathrm{Ti}^{2+}$ would not.

The above analysis could be extended to all metals. It is expected that metal charge states with ionisation potential lower than the first ionisation potential of the process gas would have a high concentration. Table 1 lists the maximum charge state which would escape a charge exchange reaction with Argon. Charge states beyond the listed ones are expected to be depleted strongly. 
Table 1. Maximum charge state $(\mathrm{Q})$ unaffected by the presence of $\mathrm{Ar}$

\begin{tabular}{cccccccccccc}
\hline No. & Name & Q & No. & Name & Q & No. & Name & Q & No. & Name & Q \\
\hline 6 & $\mathrm{C}$ & 1 & 24 & $\mathrm{Cr}$ & 1 & 33 & $\mathrm{As}$ & 2 & 46 & $\mathrm{Pd}$ & 1 \\
12 & $\mathrm{Mg}$ & 2 & 25 & $\mathrm{Mn}$ & 2 & 34 & $\mathrm{Se}$ & 1 & 47 & $\mathrm{Ag}$ & 1 \\
13 & $\mathrm{Al}$ & 2 & 26 & $\mathrm{Fe}$ & 1 & 39 & $\mathrm{Y}$ & 2 & 44 & $\mathrm{Cd}$ & 1 \\
14 & $\mathrm{Si}$ & 1 & 27 & $\mathrm{Co}$ & 1 & 40 & $\mathrm{Zr}$ & 2 & 49 & $\mathrm{In}$ & 1 \\
21 & $\mathrm{Sc}$ & 2 & 29 & $\mathrm{Cu}$ & 1 & 41 & $\mathrm{Nb}$ & 2 & 50 & $\mathrm{Sn}$ & 2 \\
22 & $\mathrm{Ti}$ & 2 & 30 & $\mathrm{Zn}$ & 1 & 42 & $\mathrm{Mo}$ & 1 & 51 & $\mathrm{Sb}$ & 2 \\
23 & $\mathrm{~V}$ & 2 & 32 & $\mathrm{Ge}$ & 2 & 44 & $\mathrm{Ru}$ & 1 & 52 & $\mathrm{Te}$ & 2 \\
\hline
\end{tabular}

Charge exchange collisions with atoms of the same metal like $C r^{2+}+C r \rightarrow C r^{1+}+C r^{1+}+\Delta E$ are also very likely because energy defect in this reaction is always positive The probability is governed by the mean free path and is higher for materials having a high sputter yield which generate high densities of metal vapour.

It has been shown that double charged ions are generated in stepwise ionisation collisions [22]. The presence of metal vapour with low ionisation potential increases the frequency of inelastic ionizing collisions, resulting in cooling of plasma electrons. This in turn strongly reduces the production of ions of higher ionisation states such as $\mathrm{Cr}^{2+}$ and $\mathrm{Ti}^{2+}$ considering that a fraction of the ionization is done by the Maxwellian portion of the EEDF. The presence of metal vapour will also affect the hotter, non-Maxwellian part of the EEDF, namely by electron- (metal) atom collisions as well as via electron-electron interaction (cooling of hot electrons). Measurements of the local EEDF are needed to further refine the detailed ionization mechanism. It is clear, though, that the relatively dense HIPIMS plasma assumes intermediate properties between the highly non-Maxwellian glow discharge EEDF and the Maxwellian EEDF of metal arcs.

It is interesting to note that ${ }^{52} \mathrm{Cr}$ and ${ }^{48} \mathrm{Ti}$ have similar mass as ${ }^{40} \mathrm{Ar}$ and as such have similar sputtering yields under Ar and self-sputtering conditions. Since $\mathrm{Cr}$ has a significantly greater sputtering yield $\left(\mathrm{Y}_{\mathrm{S}}=1.8\right.$ for $\left.1000 \mathrm{eV} \mathrm{Ar}^{1+}\right)$ than $\mathrm{Ti}\left(\mathrm{Y}_{\mathrm{S}}=0.7\right.$ for $\left.870 \mathrm{eV} \mathrm{Ar}^{1+}\right)$, the $\mathrm{Cr}$ plasma electrons are cooler [18] and the measured content of $\mathrm{Cr}^{2+}$ ions is lower compared to $\mathrm{Ti}^{2+}$, contrary to the trend observed for the respective singly charged ions. 
The presence of metal vapour also suppresses the production of $\mathrm{Ar}^{2+}$ ions, which have a higher second ionisation energy than chromium and titanium. As mentioned before, the quantity of $\mathrm{Ar}^{2+}$ is determined from the balance of production (ionization) and reduction (recombination and charge exchange). Interestingly, the doubly ionized gas ions are only observed at longer distances where the neutral metal vapour density is lower. $\mathrm{Ar}^{2+}$ ions can be created through direct and multi-step processes. In the case of HIPIMS of Ti, Fig. 4(b), the fraction of $\mathrm{Ar}^{2+}$ rises at shorter distances and reaches greater values due to the smaller amount of metal vapour compared to $\mathrm{Cr}$ (Fig. 4(a)). Furthermore, the presence of metal vapour may lead to charge exchange reactions between $\mathrm{Ar}^{2+}$ and metal neutral species:_ $A r^{2+}+C r^{0} \rightarrow A r^{1+}+C r^{1+}+\Delta E$, where $\Delta E=22 e V>0 \_$and thus reduce the number of double-charged gas ions. Finally, such reactions may be responsible for a significant anisotropy in the spatial distribution of $\mathrm{Ar}^{2+}$ ions. In summary, the behaviour of $\mathrm{Ar}^{2+}$ would be observed for practically all target materials, since all metals exhibit a smaller first ionisation potential.

The lower content of metal ions at the shortest distance of $50 \mathrm{~mm}$ compared to $75 \mathrm{~mm}$ can be attributed to the small number of collisions that metal atoms undergo whilst traversing the rarefied atmosphere created initially by the sputter wind. The reduced scattering and therefore retained velocity make ionizing collisions with electrons less likely. When the atoms are slowed by elastic collisions, their local residence time and density increases and ionisation by electron impact becomes more likely. This could explain the reversal of metal ion content at $50 \mathrm{~mm}$ where the absolute flux of $\mathrm{Ti}^{1+}$ ions was greater than $\mathrm{Cr}^{1+}$ (compare Figures $3 \mathrm{~b}$ and $3 \mathrm{a}$ ) in contrast to longer distances. Although a larger number of atoms are sputtered from the target, less $\mathrm{Cr}$ ions are formed in its vicinity at $50 \mathrm{~mm}$. For Ti, with less sputter wind and gas rarefaction, collisions with Ar atoms are more likely, which increases the residence time and the number of ionisation events close to the target. Therefore, although the flux of Ti atoms is smaller than in the case of $\mathrm{Cr}$, there is nevertheless a higher density of $\mathrm{Ti}$ ions. The $\mathrm{Cr}$ atoms are slowed down at larger 
distances, where their ionisation frequency is larger, giving a higher ion content at larger distances from the target compared to the Ti case.

The plasma analyzer may affect the plasma production to some degree, especially when the orifice is closer than several target radii from the target surface. The grounded orifice of the spectrometer may penetrate the outer parts of the magnetic confinement field and drain electrons from the plasma region. Those electrons could have contributed to plasma production and metal ionisation. The reduced amount of metal ions in the measurement near the target may therefore be a result of the interaction of the plasma discharge with the plasma spectrometer. Thus, measurements are limited to a region outside the immediate closed drift zone.

The energy of metal ions is determined by the initial kinetic energy of atoms resulting from the sputtering process $[13,20]$, the electric field in the magnetic sheath (the zone where $\mathbf{E} \times \mathbf{B}$ closed drift occurs), and by collisions with the low energy Ar atoms.

The above discussions have established that gas rarefaction plays a significant role in the transport of metal species to the target. An important factor influencing gas rarefaction is the area of the target. Large size targets are operated at high power which is transferred to the gas and results in more heating and higher degree of gas rarefaction. Thus the measurements in this paper should be regarded in terms relative to the target size of $\varnothing 50 \mathrm{~mm}$. We have shown in Figure 3 and Section 3.1 that a Cr-rich plasma is maintained at a distance of up to $\sim 200 \mathrm{~mm}$, and Ti-rich plasma up to a distance of $\sim 120 \mathrm{~mm}$. These are equivalent to 4 and 2.4 times the target diameter for $\mathrm{Cr}$ and $\mathrm{Ti}$ respectively. It is expected that larger targets could sustain a metal-rich plasma over longer distances.

The fact that the magnetron is balanced limits ion transport into the chamber. In the case of unbalancing the magnetic field [23] and reducing its strength [24], an enhanced ion flux of metal can be observed at longer distances.

In practical terms, the presented results give some hints on how to best utilize the flux of ionic species. It has been previously reported that the degree of metal ionisation in HIPIMS is 
constant with distance from the target [12]. Clearly, to utilize metal ions for self-ion assisted deposition and minimise gas ion bombardment, a relatively short distance between target and substrate is desirable. The optimum distance is different for $\mathrm{Ti}$ and $\mathrm{Cr}$, respectively and may depend on the target size, the magnetic field strength on the target surface and the degree of unbalancing of the magnetron. If gas ion assisted deposition is deemed beneficial, a larger distance is preferred. This has to be weighed with other factors such as deposition rate, coating homogeneity and interplay with reactive species. This work shows that the use of HIPIMS introduces several complications for the practitioner interested in optimizing the benefits from the increased ionisation compared to cathodic arc deposition. Further research and development of models will have to account for the individual behaviours of different metals in this regard.

As a final remark, we agree that the transport of ion species from the target to the substrate proceeds according to ambipolar diffusion laws [12]. This process is effectively governed by magnetic fields because one type of the diffusing particles, the electrons, is magnetized, and therefore impeding cross-field motion.

We have shown that the sputtering yield of the target material is a significant factor. The yield strongly affects collision processes and controls both the gas rarefaction effect and the existence of higher charged gas ions.

\section{Conclusions}

Titanium and chromium HIPIMS plasmas have been investigated with a HIDEN plasmasampling energy-resolving mass spectrometer at different distances from the sputtering target. Measurements of the argon and metal ion content as well as the ion energy distribution functions showed for the specific power density and pulse length used that (1) singly and doubly charged ions were found for argon as well as the target metal, (2) the majority of ions were singly charged 
argon ions for both metal targets and for all distances investigated, (3) the $\mathrm{Cr}$ ion density extended to further distances from the target than the Ti ion density.

The high density of metal vapour in $\mathrm{Cr}$ caused displacement of the $\mathrm{Ar}$ gas, i.e. argon gas rarefaction in the vicinity of the target, whereas the rarefaction was less evident in the Ti case. The presence of metal vapour was found to be consistent with cooling of the plasma electrons and charge exchange leading to suppression of the formation as well as to a charge reduction of higher charged ions, especially $\mathrm{Ar}^{2+}$ ions. High charge states of metals with a second ionisation potential higher than the first ionisation potential of the process gas were suppressed due to charge exchange collisions.

\section{Acknowledgements}

The financial support of EPSRC in the framework of Grant No. EP/D049202/1 is gratefully acknowledged. Work at Lawrence Berkeley National Laboratory was supported by the U.S. Department of Energy under Contract No. DE-AC02-05CH11231. JA acknowledges the support of the SSF Strategic Research Centre on Materials Science for Nanoscale Surface Engineering $\mathrm{MS}^{2} \mathrm{E}$ and Wenner-Gren Foundations. 


\section{References}

[1] Ehiasarian A P, Hovsepian P E, Hultman L and Helmersson U 2004 Thin Solid Films 457 270-7

[2] Hovsepian P E, Reinhard C and Ehiasarian A P 2006 Surf Coat Technol 201 4105-10

[3] Lattemann M, Ehiasarian A P, Bohlmark J, Persson P A O and Helmersson U 2006 Surf Coat Technol 200 6495-9

[4] Helmersson U, Lattemann M, Bohlmark J, Ehiasarian A P and Gudmundsson J T 2006 Thin Solid Films 513 1-24

[5] Alami J, Eklund P, Andersson J M, Lattemann M, Wallin E, Bohlmark J, Persson P and Helmersson U 2007 Thin Solid Films 515 3434-8

[6] Hovsepian P E, Ehiasarian A P, Deeming A and Schimpf C 2008 Vacuum 82 1312-7

[7] Konstantinidis S, Hemberg A, Dauchot J P and Hecq M 2007 J.Vac.Sci Technol. B 25 19-21

[8] Bilek M M M and McKenzie D R 2006 Surf Coat Technol 200 4345-54

[9] Anders A 2008 Cathodic Arcs: From Fractal Spots to Energetic Condensation (New York: Springer)

[10] Anders A, Andersson J and Ehiasarian A 2007 J.Appl.Phys. 102113303

[11] Anders A, Andersson J and Ehiasarian A 2008 J.Appl.Phys. 103039901

[12] de Poucques L, Imbert J C, Boisse-Laporte C, Bretagne J, Ganciu M, Teule-Gay L and Touzeau M 2006 Plasma Sources Sci. Technol. 15 661-9

[13] Hecimovic A, Burcalova K and Ehiasarian A P 2008 J.Phys.D 41095203

[14] Vitelaru C, Aniculaesei C, De Poucques L, Minea T M, Boisse-Laporte C, Bretagne J, Popa G 2010 J.Phys.D:Appl.Phys. 43124013

[15] Kadlec S 2007 Plasma Process Polym. 4 S419-23

[16] Horwat D and Anders A 2008 J.Phys.D 41135210

[17] Hecimovic A and Ehiasarian A P "Spatial and temporal evolution of ion energies in HIPIMS plasma discharge" 2009 J.Appl.Phys. accepted for publication

[18] Vetushka A and Ehiasarian A P 2008 J.Phys.D 41015204

[19] Rossnagel S M 1988 J.Vac.Sci Technol. A 6 19-24 
[20] Behrisch R 1981 Sputtering by Particle Bombardment. I, Physical Sputtering of SingleElement Solids (Berlin: Springer)

[21] Guimaraes F, Almeida J, Bretagne J 1991 J.Vac.Sci.Technol. A. 9 133-40

[22] Ehiasarian AP, Vetushka A, Hecimovic A, Konstantinidis S 2008 J.Appl.Phys. 104083305

[23] Vlcek J, Kudlacek P, Burcalova K and Musil J 2007 J.Vac.Sci Technol. A 25 42-7

[24] Ehiasarian A P and Vetushka A 2009 Magnetron configuration to enhance deposition rate in high power impulse magnetron sputtering. In: SVC, Society of Vacuum Coaters - 52nd Annual Technical Conference, May 9-14, 2009, (Santa Clara, CA, United states ) pp 265-70 


\section{Figure Captions}

Figure 1. Schematic presentation of the experimental apparatus showing the magnetron gun mounted on a moveable shaft and the fixed energy-resolving mass spectrometer.

Figure 2. Voltage and current of HIPIMS discharges of (a) Cr and (b) Ti at 4.8 mTorr (0.64 Pa)

Figure 3. Ion count rate (integrated over the energy distribution function) as a function of distance from the target for HIPIMS of (a) $\mathrm{Cr}$ and (b) Ti.

Figure 4. Normalised ion content as a function of distance from the target for HIPIMS of (a) $\mathrm{Cr}$ and (b) Ti. Lines are drawn to guide the eye and not to define local minima and maxima.

Figure 5. Ion energy distribution functions of $\mathrm{Ar}^{1+}$ ions in HIPIMS discharges utilizing (a) $\mathrm{Cr}$ and (b) Ti targets. Ion energies are presented in electronvolts corresponding to the potential settings within the mass spectrometer.

Figure 6. Ion energy distribution functions of $\mathrm{Cr}^{1+}$ ions in HIPIMS with a chromium target. Ion energies are presented in electronvolts corresponding to the potential settings within the mass spectrometer.

Figure 7. Ion energy distribution functions of $\mathrm{Ti}^{1+}$ ions in HIPIMS with a titanium target. Ion energies are presented in electronvolts corresponding to the potential within the mass spectrometer. 


\section{Table Captions:}

Table 1. Maximum charge state (Q) unaffected by the presence of $\mathrm{Ar}$ 
Table 1. Maximum charge state $(\mathrm{Q})$ unaffected by the presence of $\mathrm{Ar}$

\begin{tabular}{cccccccccccc}
\hline No. & Name & Q & No. & Name & Q & No. & Name & Q & No. & Name & Q \\
\hline 6 & $\mathrm{C}$ & 1 & 24 & $\mathrm{Cr}$ & 1 & 33 & $\mathrm{As}$ & 2 & 46 & $\mathrm{Pd}$ & 1 \\
12 & $\mathrm{Mg}$ & 2 & 25 & $\mathrm{Mn}$ & 2 & 34 & $\mathrm{Se}$ & 1 & 47 & $\mathrm{Ag}$ & 1 \\
13 & $\mathrm{Al}$ & 2 & 26 & $\mathrm{Fe}$ & 1 & 39 & $\mathrm{Y}$ & 2 & 44 & $\mathrm{Cd}$ & 1 \\
14 & $\mathrm{Si}$ & 1 & 27 & $\mathrm{Co}$ & 1 & 40 & $\mathrm{Zr}$ & 2 & 49 & $\mathrm{In}$ & 1 \\
21 & $\mathrm{Sc}$ & 2 & 29 & $\mathrm{Cu}$ & 1 & 41 & $\mathrm{Nb}$ & 2 & 50 & $\mathrm{Sn}$ & 2 \\
22 & $\mathrm{Ti}$ & 2 & 30 & $\mathrm{Zn}$ & 1 & 42 & $\mathrm{Mo}$ & 1 & 51 & $\mathrm{Sb}$ & 2 \\
23 & $\mathrm{~V}$ & 2 & 32 & $\mathrm{Ge}$ & 2 & 44 & $\mathrm{Ru}$ & 1 & 52 & $\mathrm{Te}$ & 2 \\
\hline
\end{tabular}


Figure Captions

Figure 1. Schematic presentation of the experimental apparatus showing the magnetron gun mounted on a moveable shaft and the fixed energy-resolving mass spectrometer.

Figure 2. Voltage and current of HIPIMS discharges of (a) Cr and (b) Ti at 4.8 mTorr (0.64 $\mathrm{Pa})$

Figure 3. Ion count rate (integrated over the energy distribution function) as a function of distance from the target for HIPIMS of (a) $\mathrm{Cr}$ and (b) Ti.

Figure 4. Normalised ion content as a function of distance from the target for HIPIMS of (a) $\mathrm{Cr}$ and (b) Ti. Lines are drawn to guide the eye and not to define local minima and maxima.

Figure 5. Ion energy distribution functions of $\mathrm{Ar}^{1+}$ ions in HIPIMS discharges utilizing (a) $\mathrm{Cr}$ and (b) Ti targets. Ion energies are presented in electronvolts corresponding to the potential settings within the mass spectrometer.

Figure 6. Ion energy distribution functions of $\mathrm{Cr}^{1+}$ ions in HIPIMS with a chromium target. Ion energies are presented in electronvolts corresponding to the potential settings within the mass spectrometer.

Figure 7. Ion energy distribution functions of $\mathrm{Ti}^{1+}$ ions in HIPIMS with a titanium target. Ion energies are presented in electronvolts corresponding to the potential within the mass spectrometer. 


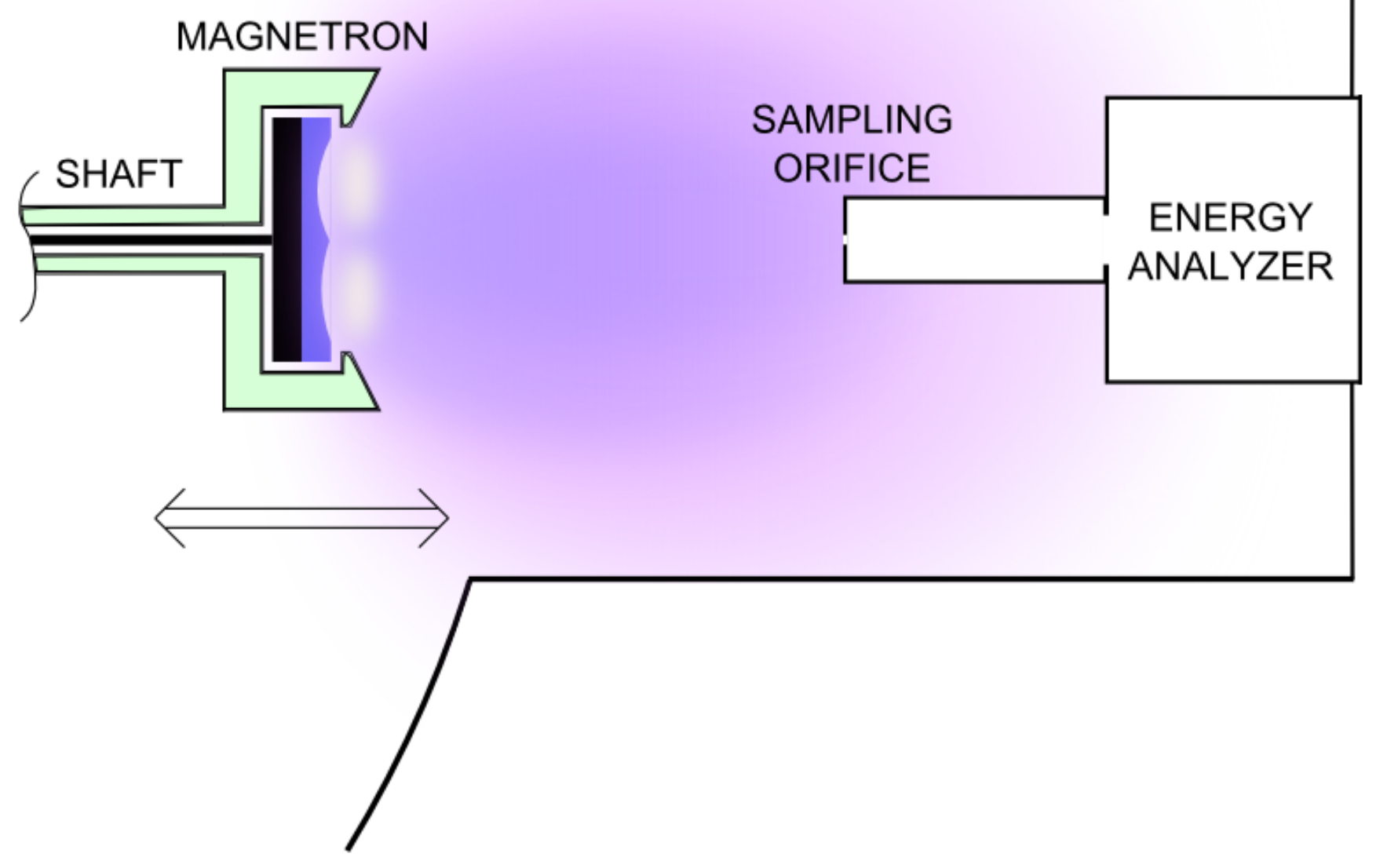

Figure 1 (Figure1.tif) 


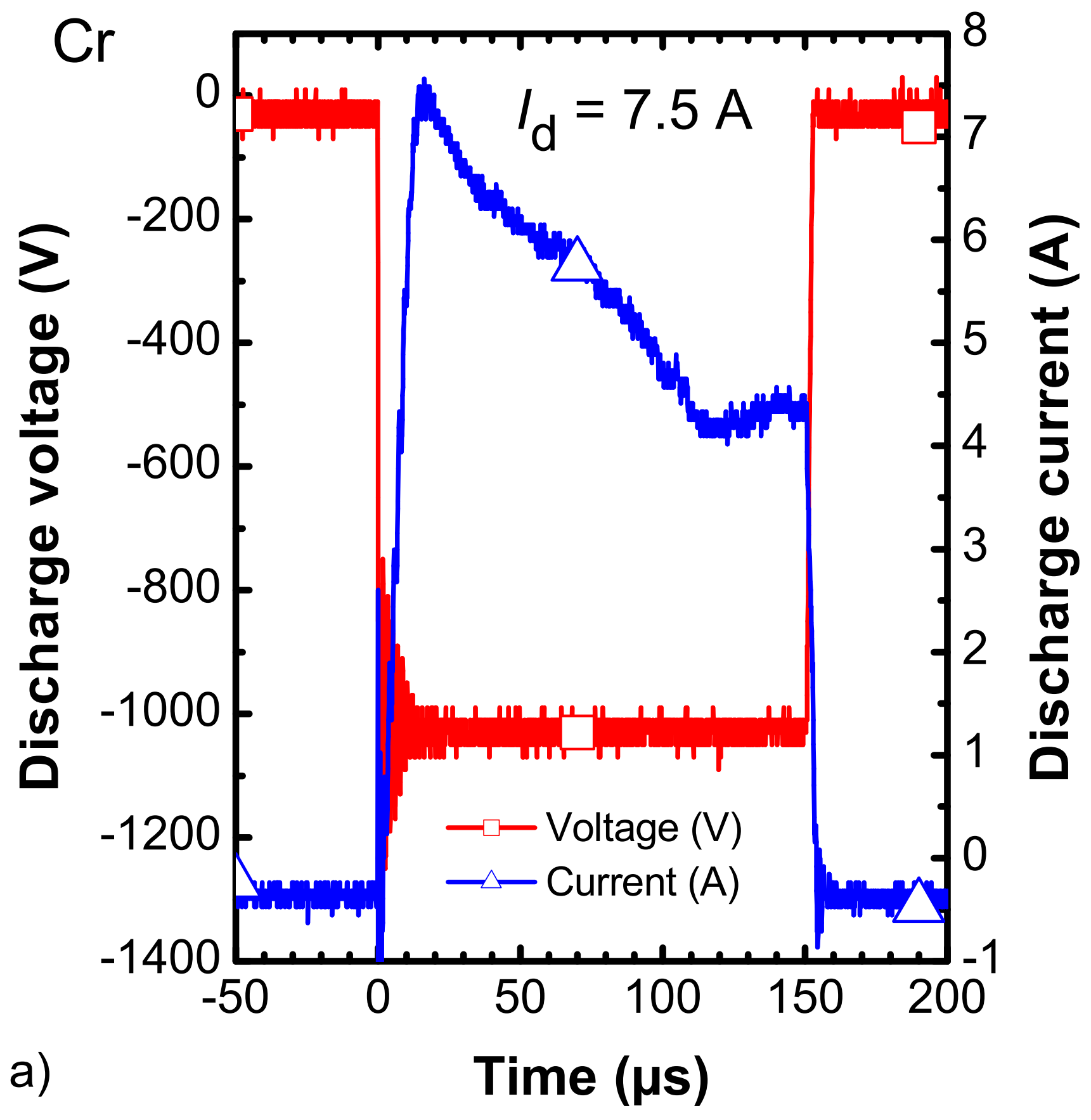

Figure 2 (Figure2a.EPS) 


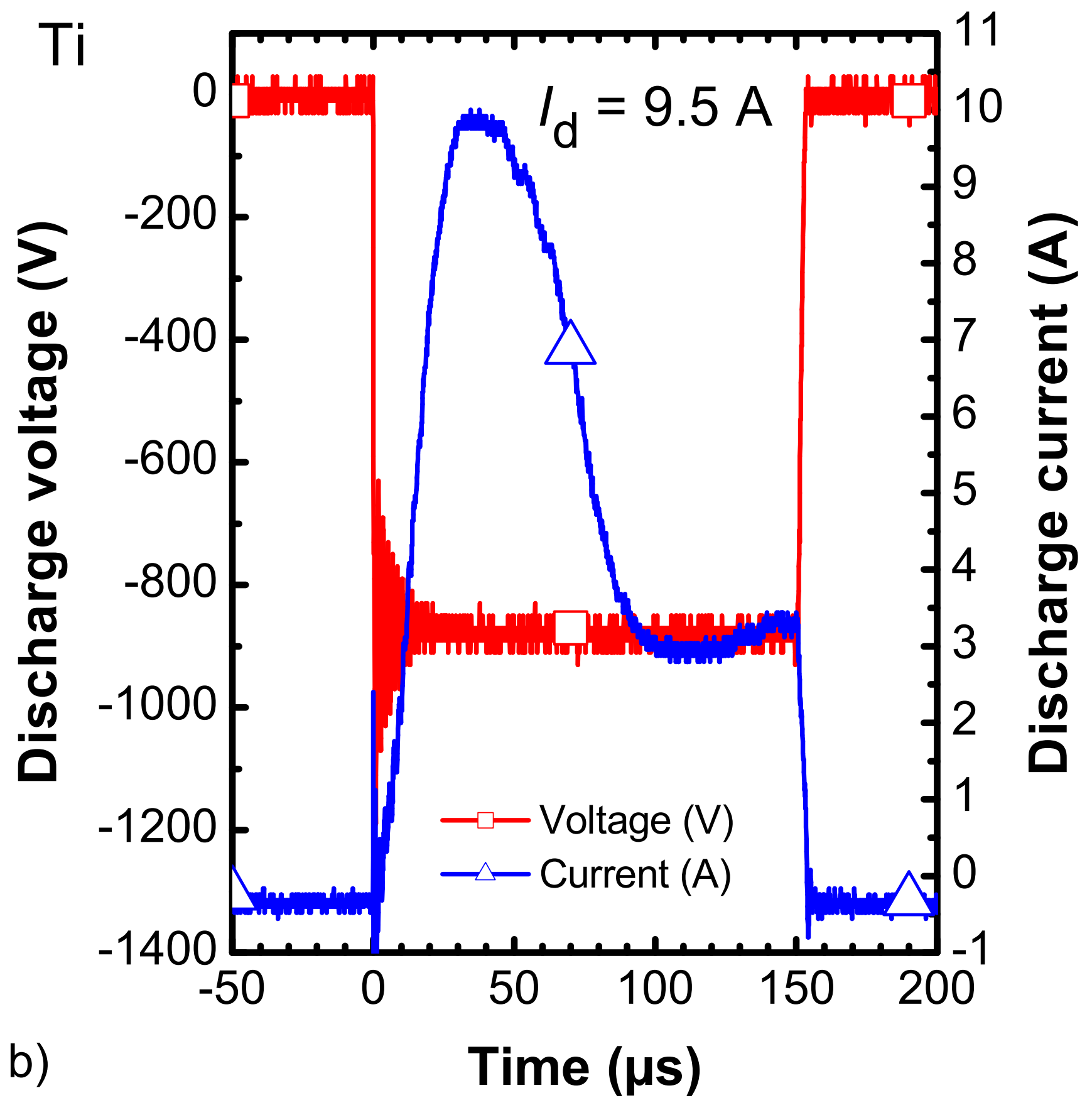

Figure 3 (Figure2b.EPS) 


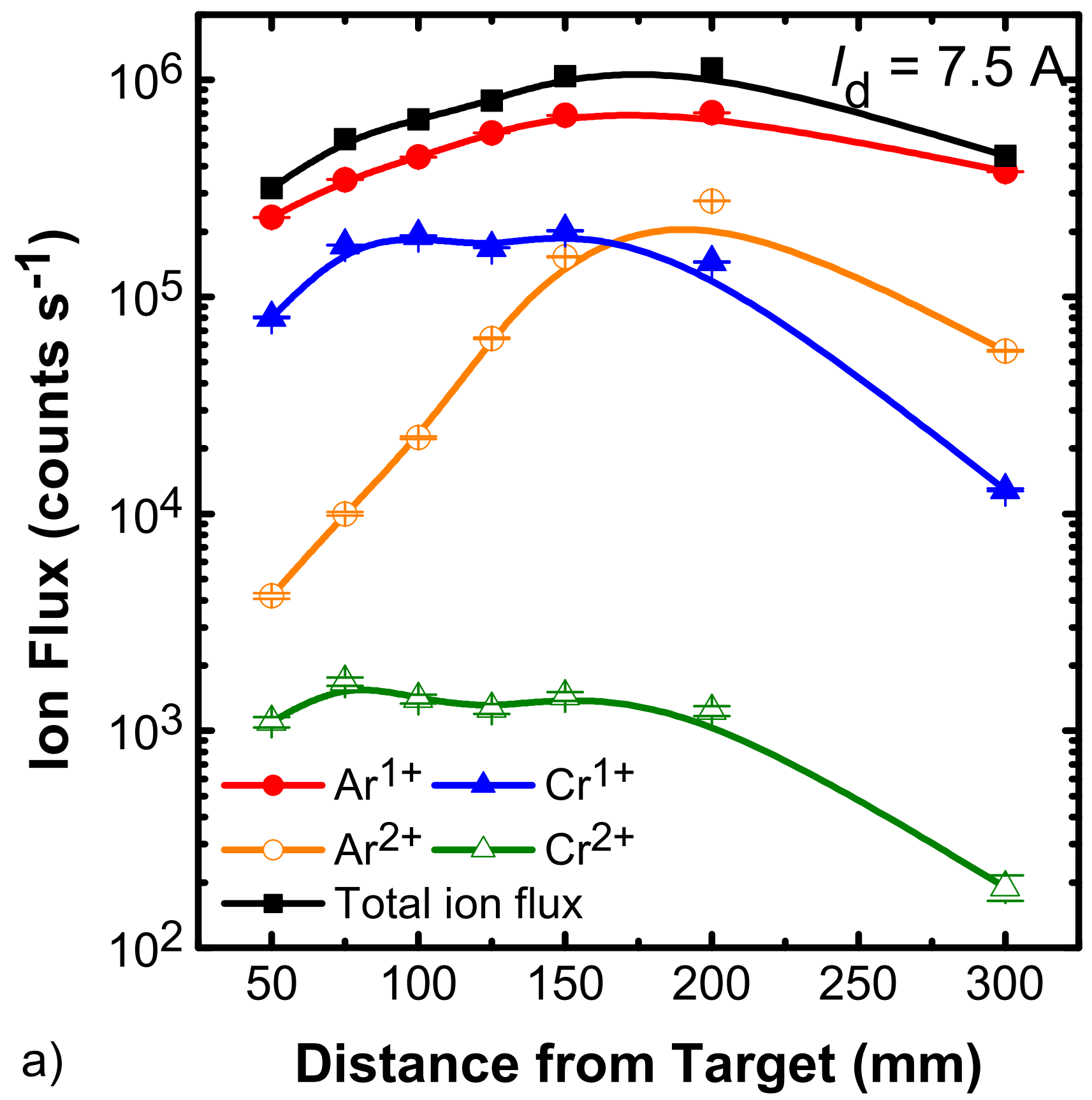

Figure 4 (Figure3aerror.EPS) 


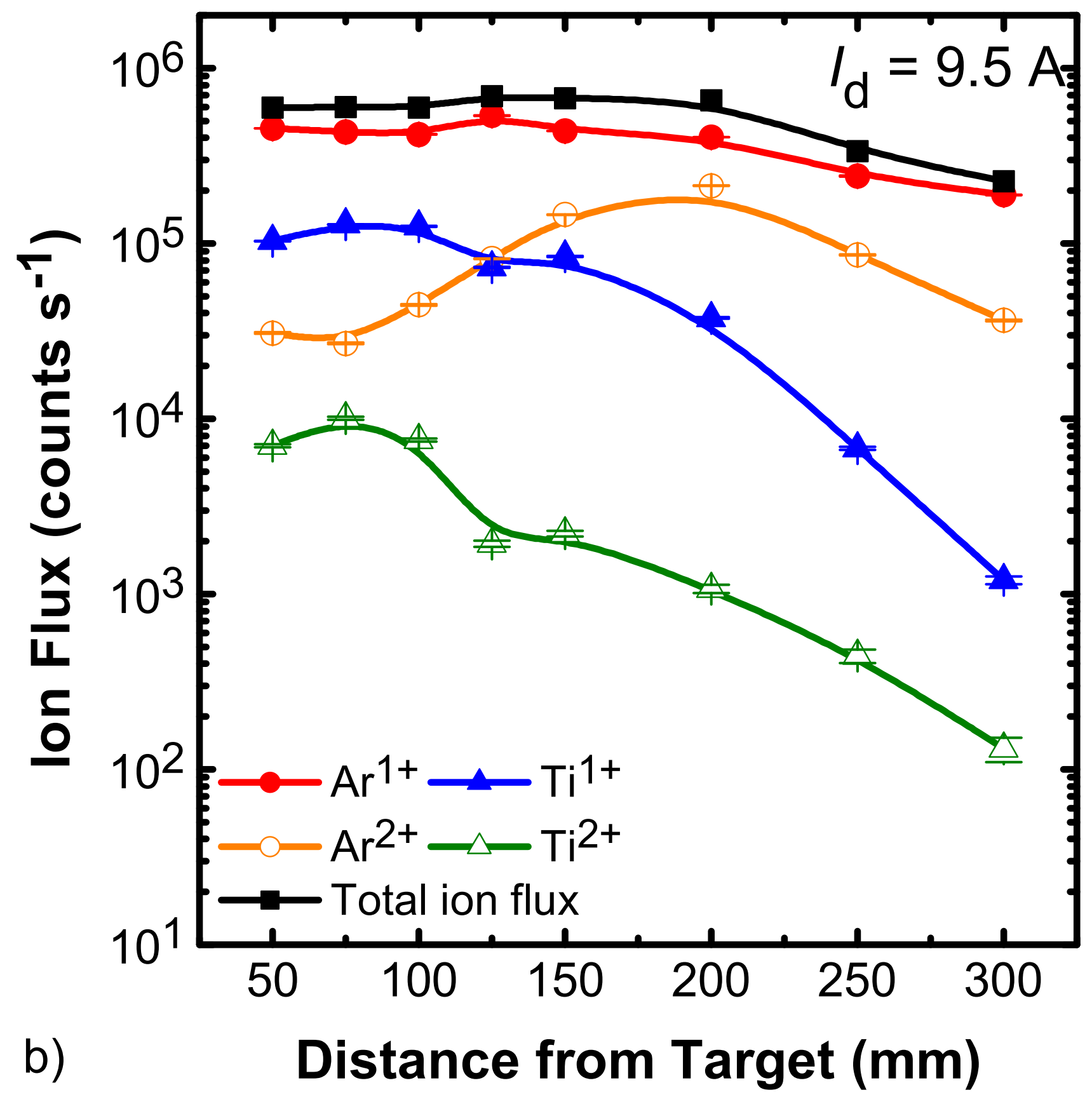

Figure 5 (Figure3berror.EPS) 


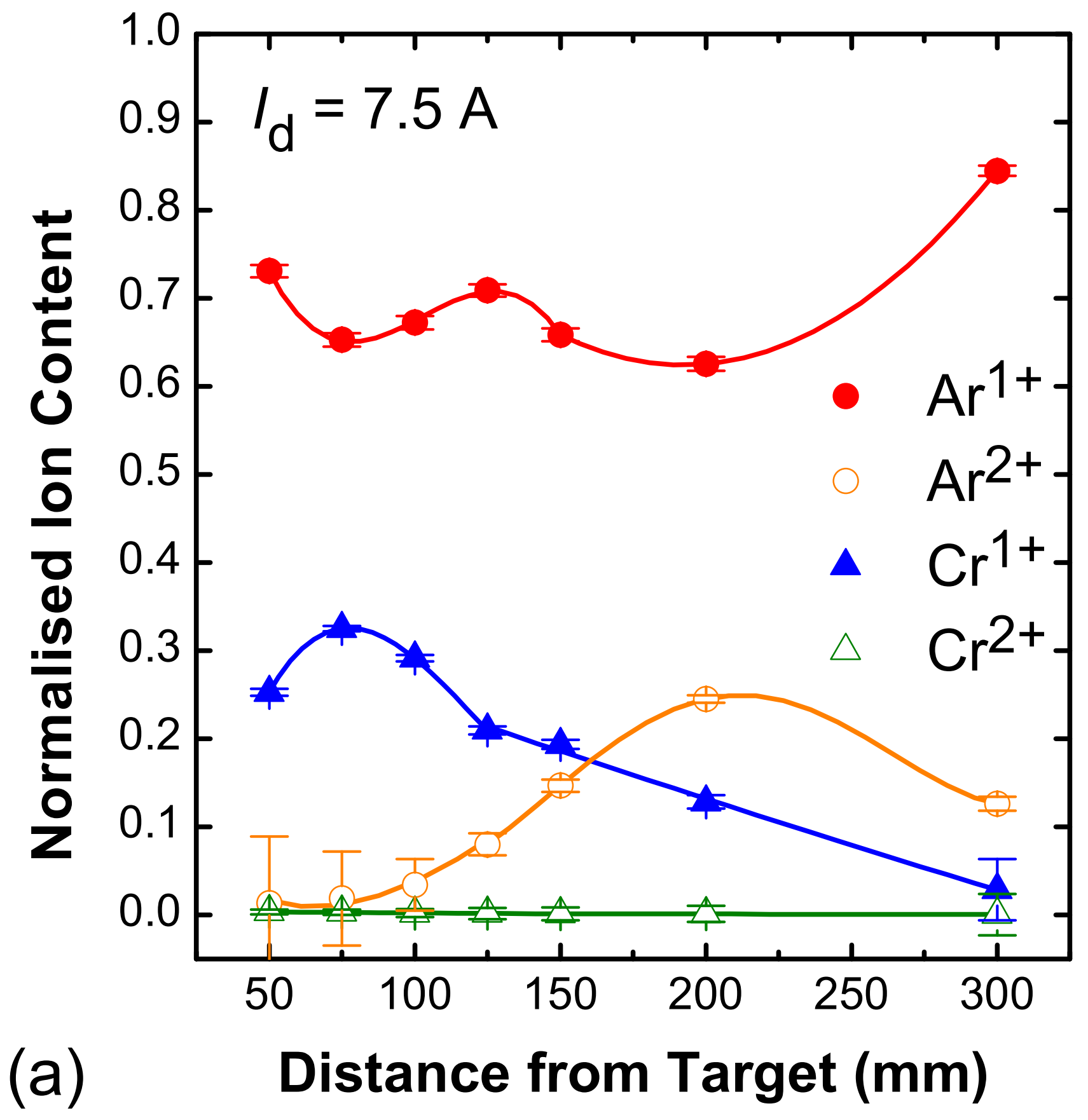

Figure 6 (Figure4aerror.EPS) 


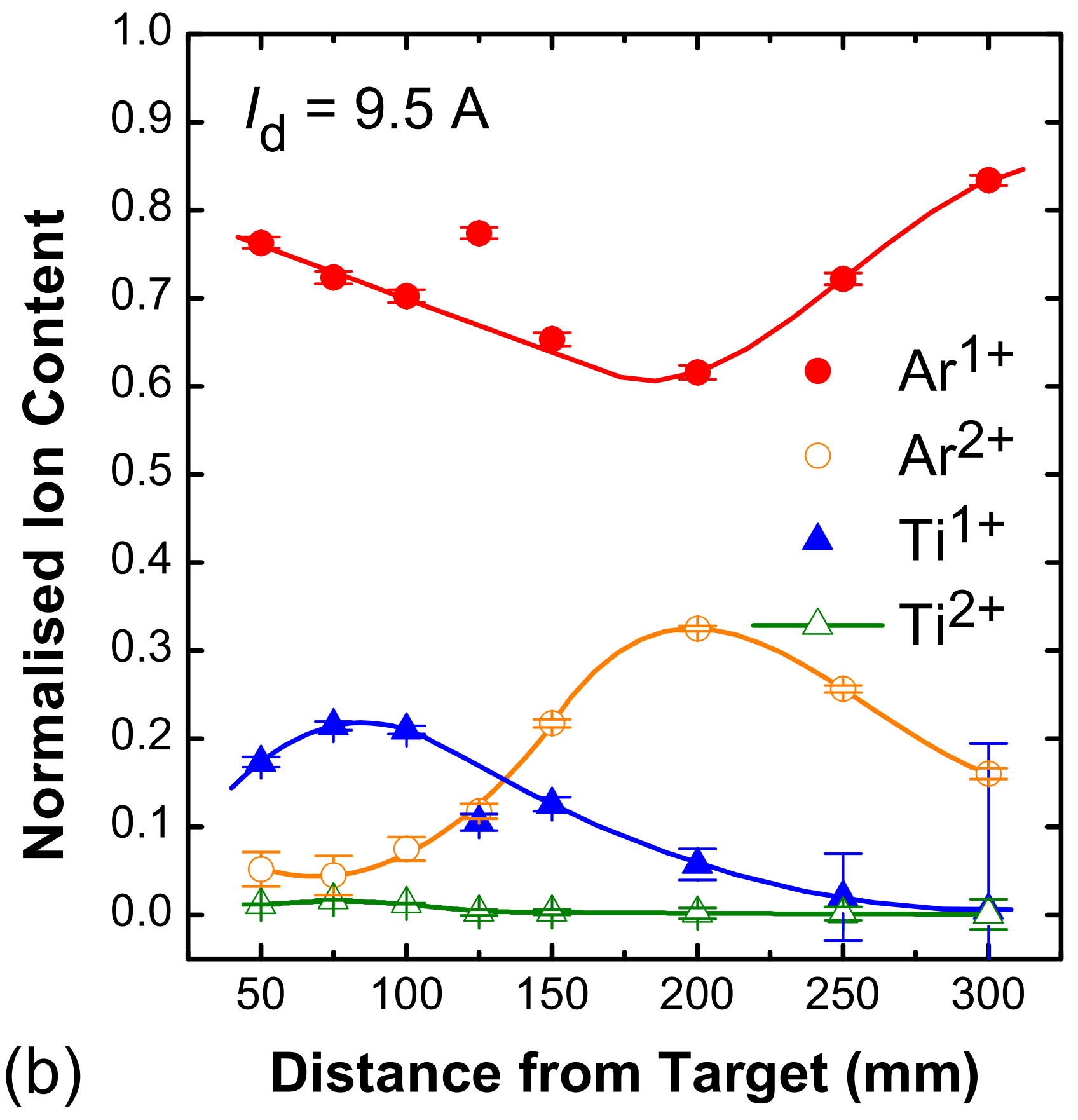

Figure 7 (Figure4berror.EPS) 


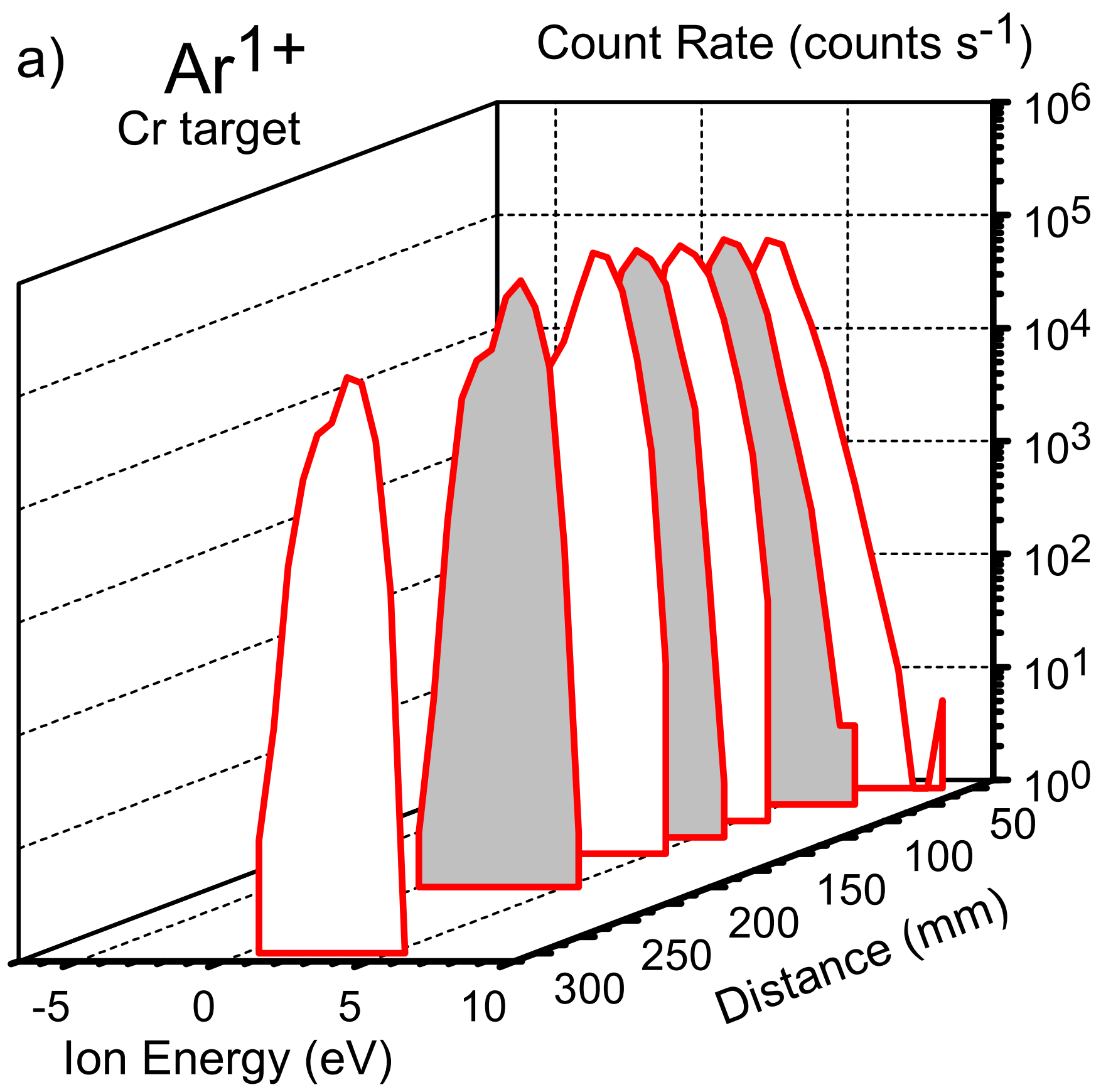

Figure 8 (Figure5a.EPS) 


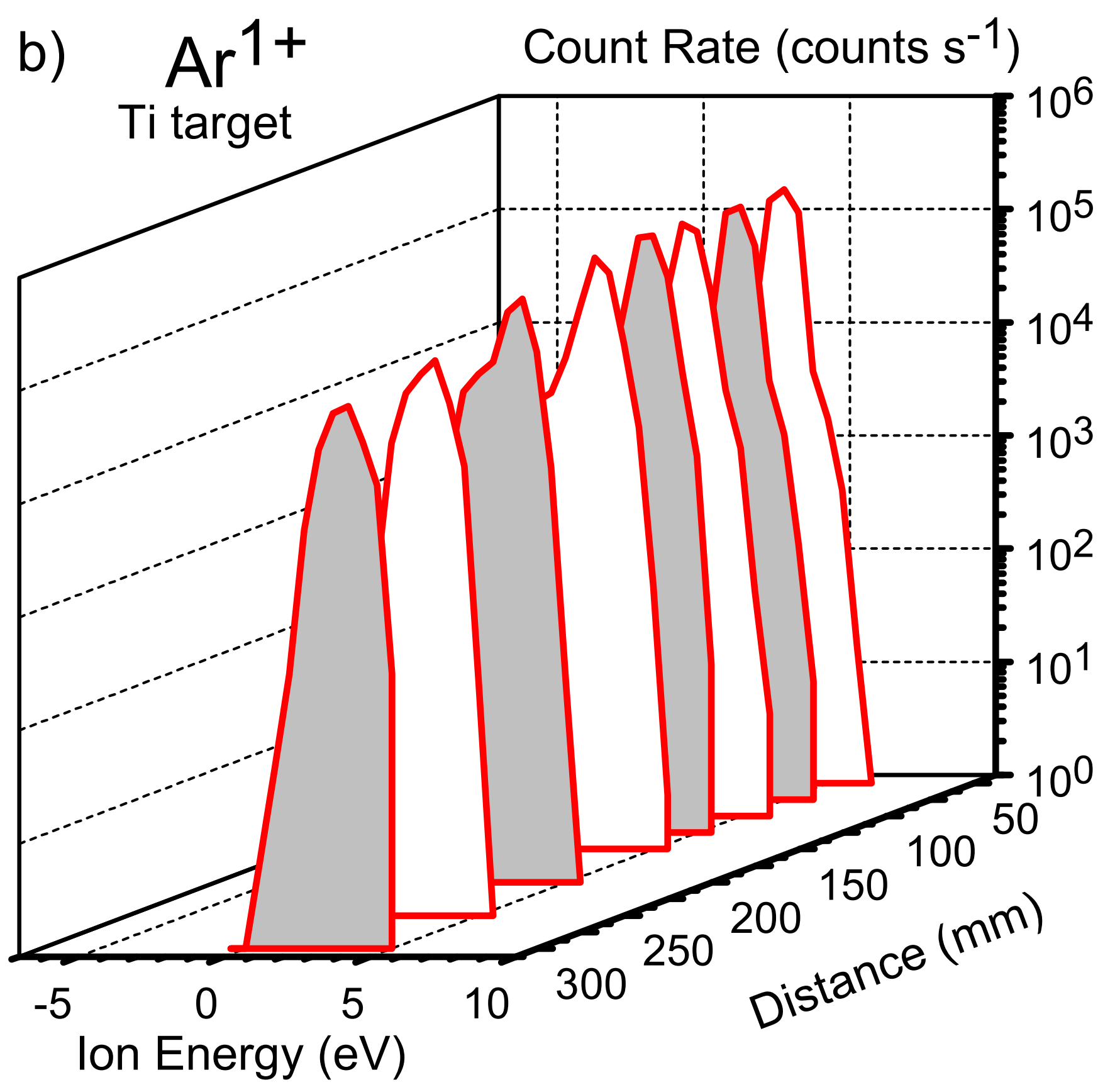

Figure 9 (Figure5b.EPS) 


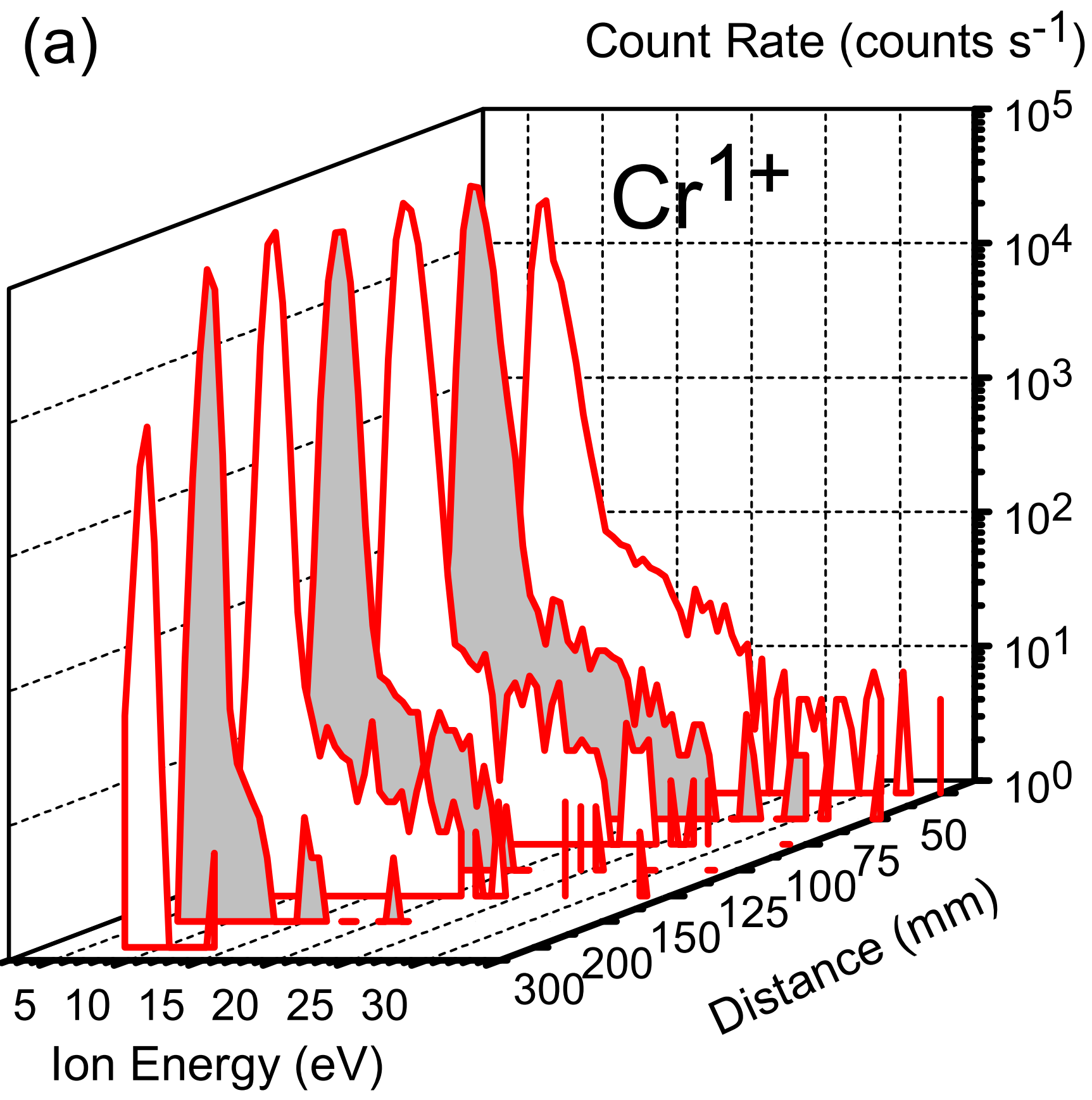

Figure 10 (Figure6a.EPS) 


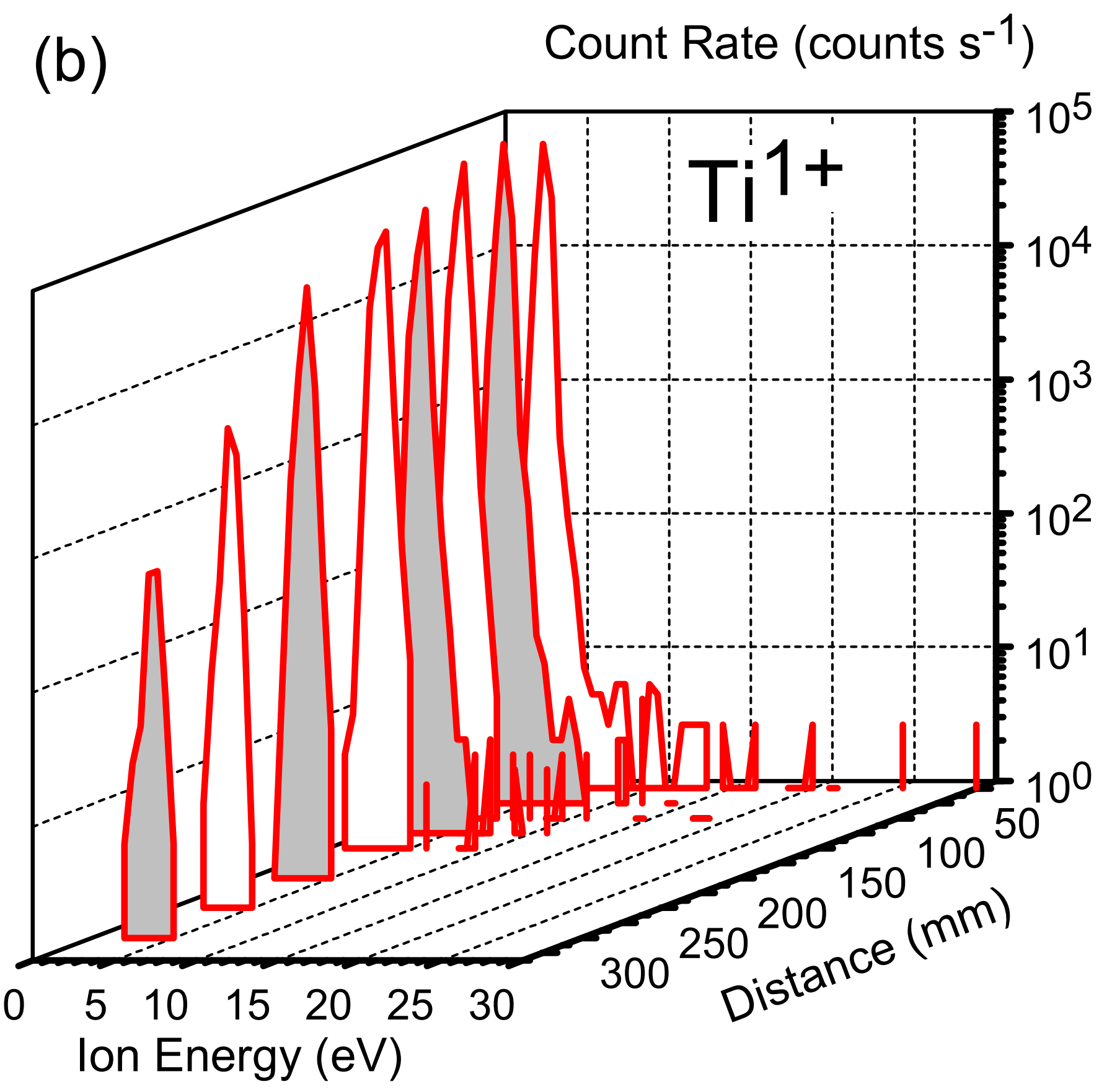

Figure 11 (Figure6b.EPS) 